\title{
Probiotics in aquaculture of China - Current state, problems and prospect
}

\author{
Zizhong Qi ${ }^{a}$, Xiao-Hua Zhang ${ }^{\mathrm{a}, *}$, Nico Boon $^{\mathrm{b}}$, Peter Bossier ${ }^{\mathrm{c}}$ \\ a Department of Marine Biology, Ocean University of China, Qingdao, China \\ ${ }^{\mathrm{b}}$ Laboratory of Microbial Ecology and Technology (LabMET), Ghent University, Gent, Belgium

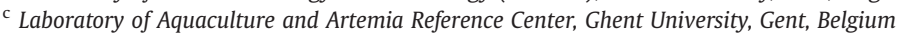

\section{A R T I C L E I N F O}

\section{Article history:}

Received 10 July 2008

Received in revised form 3 February 2009

Accepted 8 February 2009

\section{Keywords:}

Probiotics

Aquaculture

China

Quality control

\begin{abstract}
A B S T R A C T
The development of non-antibiotic and environmental friendly agents is one of the key factors for health management in aquaculture. The application of probiotics in aquaculture of China emerged in 1980s; subsequently, commercial probiotic products from USA, Japan and United Kingdom were introduced into China in the middle of 1990s and evaluation experiments were conducted in vivo. In the mean time, scientists in China started to screen for new probiotic strains from local aquaculture rearing unit in an attempt to suit the specific requirements in China. Also, different modes of action of probiotics were studied. As products containing probiotic bacteria are gaining popularity in aquaculture of China, the quality control of probiotics in aquaculture has become an important issue in China. At present, data about the efficacy of probiotics in commercial aquaculture of China are still lacking. This review discusses mainly the studies and applications about species, effects, mechanisms, problems and prospect of probiotics used in aquaculture of China, and highlighted several effective evaluation methods to control the quality of commercial probiotic products.
\end{abstract}

(c) 2009 Elsevier B.V. All rights reserved.

\section{Introduction}

Today, aquaculture is the fastest growing food-producing sector in the world, with an average annual growth rate of $8.9 \%$ since 1970 , compared to only $1.2 \%$ for capture fisheries and $2.8 \%$ for terrestrial farmed meat production systems over the same period (Subasinghe, 2005). World aquaculture has grown tremendously during the last fifty years from a production of less than a million tonne in the early 1950s to 59.4 million tonnes by 2004. This level of production had a value of US\$70.3 billion. Of this production, 41.3 million tonnes, or $69.6 \%$, was produced in China and $21.9 \%$ in the rest of Asia and the Pacific region (FAO, 2006).

China is one of the most important contributors to world aquaculture production. Marine capture fisheries were most important until the 1980s, when the fisheries authority of China, being aware that many major marine fishery resources were being depleted, shifted its priority from wild fishing to aquaculture. As a result of this significant shift, aquaculture development has accelerated throughout the country. Since 1993, aquaculture has accounted for more than half of the country's aquatic production, making China the largest producer of aquatic products in the world. Mariculture in China may date back to the Song Dynasty about 1000 years ago, involving cultivation of a kind of seaweed called glueweed, Gloiopeltis furcata, by a simple rock-cleaning method in Jinmen, Fujian Province (Tseng,

\footnotetext{
* Corresponding author. Department of Marine Biology, Ocean University of China, 5 Yushan Road, Qingdao 266003, China. Tel.: +86532 82032767; fax: +8653282032767. E-mail address: xhzhang@ouc.edu.cn (X.-H. Zhang).
}

1993). The intense development of mariculture started only 3 decades ago. Thus, over the last 30 years, the production of mariculture has been increasing rapidly in China from 184,000 tonnes in 1970 , to 444,000 tonnes in 1980 , to 1.6 million tonnes in 1990 , to 10.6 million tonnes in 2000, and to 13.5 million tonnes in 2005 (Zhong and Power, 1997; FAO, 2006).

Globally, aquaculture is expanding into new directions, intensifying and diversifying. With the increasing intensification and commercialization of aquaculture production, disease problems inevitably emerged. Disease is now a primary constraint to the culture of many aquatic species, impeding both economic and social development in many countries (Bondad-Reantaso et al., 2005). Infectious disease may emerge within a country in a number of ways, for example by the introduction of known exotic diseases, by sudden changes in the pattern of existing endemic diseases, or by the appearance of previously unrecognized diseases. Contingency planning, early warning and early response are critical to the effective management of such disease emergencies (FAO, 2006). Shrimp diseases in China caused US $\$ 420$ million loss in 1993 (Wei, 2002). The disease is believed to have been caused by baculovirus (hypodermal and hematopoietic necrosis baculovirus; HHNBV), which became epizootic because of the deteriorating ecological conditions (Wang et al., 1997). Fish diseases in China are mainly caused by bacterial pathogens, including Edwardsiella tarda, Vibrio anguillarum, V. harveyi, Photobacterium damselae subsp. piscicida, etc. (Xiao et al., 1999; Wang et al., 2002a, b, 2007a,b; Lan et al., 2008).

For decades, antibiotics routinely used for treatment of human infections were also used for aquatic animals, for therapy, prophylactic 
reasons or growth promotion. However, the adverse effects associated with the use of antibiotics in aquaculture are notorious. The development and spread of antimicrobial resistant human pathogens (motile Aeromonas spp., E. tarda, Escherichia coli, V. vulnificus, V. parahaemolyticus, V. cholerae etc.) were well-documented (WHO, 1999); aquatic bacteria can also develop resistance genes as a consequence of exposure to antimicrobial agents (Smith et al., 1994; Kim et al., 2004; Sørum, 2006). Also, the occurrence of antimicrobial residues in products of aquaculture threat human health (WHO, 2006). Moreover, the flatfish industry of China suffered greatly from an antibiotic residue crisis in 2006. It was estimated that at least 25,000 tonnes of turbot could not be sold and the economic losses due to this crisis were estimated to be several hundred million Euro (Lei, 2007). Thus, the indiscriminate use of antibiotics for fish has increasingly become a matter of public concern in China, and a legal framework is being enforced. However, because of the complex nature of aquatic culture systems and the diversity of culture species and pathogens, few antibiotics can be licensed for efficient and safe use. Currently, a limited number of government-approved antibiotics and chemotherapeutic agents are used for prevention and treatment of infectious aquatic diseases. At present, there is an urgent need to discover new alternatives or approaches for the abuse of antibiotics.

The use of probiotics, which control pathogens through a variety of mechanisms, is increasingly viewed as an alternative to antibiotic treatment (Verschuere et al., 2000). The term probiotic (the opposite of the term antibiotic), meaning "for life" in the original Greek Language, was previously defined by Fuller (1989) as "a live microbial feed supplement which beneficially affects the host animal by improving its intestinal microbial balance." At present, probiotics are well established for use in humans, poultry and cattle. The probiotics could be considered as veterinary medicine used for animal protein production (Irianto and Austin, 2002). In the field of aquaculture, Verschuere et al. (2000) extended the concept of probiotic as " a live microbial adjunct which has a beneficial effect on the host by modifying the host-associated or ambient microbial community, by ensuring improved use of the feed or enhancing its nutritional value, by enhancing the host response towards disease, or by improving the quality of its ambient environment". The broad definition of probiotics in the field of aquaculture was also concerned with "organic wastes" and "pollutants", as a result of incorporation of "bioremediation" and "biocontrol" when dealing with environmental problems. The goal of this review is to summarize the studies on probiotics quality control in aquaculture, the current status of using probiotic products in aquaculture in China and to outline the molecular microbial ecological tools for the enumeration of probiotics in a complex microbial community.

\section{Current status of using probiotic products in aquaculture of China}

Modern application of probiotics in Chinese aquaculture could be traced back to the 1980s following the popularity of using antibiotics. In the last 10 years, there has been an exponentially growing application of probiotics in aquaculture: at present more than hundred companies are producing many types of probiotics for aquaculture, and probably over 50,000 tonnes of commercial probiotic products are sold annually with a market value estimated at 50 million euros. The probiotics used in Chinese aquaculture are mainly photosynthetic bacteria (PSB), antagonistic bacteria (Pseudoalteromonas sp., Flavobacterium sp., Alteromonas sp., Phaeobacter sp., Bacillus sp., etc.), microorganisms for nutritional and enzymatic contribution to the digestion (lactic acid bacteria, yeast, etc.), bacteria for improving water quality (nitrifying bacteria, denitrifiers, etc.), Bdellovibrio, and other probiotics. Recently, an integrated approach by using combined probiotics (=microecologics) is gaining popularity (Wang and Wang, 2008).

\subsection{The photosynthetic bacteria}

Currently, photosynthetic bacteria are found in five bacterial phyla, i.e. Chlorobi, Cyanobacteria, Chloroflexi (filamentous anoxygenic phototrophs), Firmicutes (heliobacteria) and Proteobacteria (purple sulfur and purple non-sulfur bacteria) (Bryant and Frigaard, 2006). Traditionally in Chinese aquaculture, the photosynthetic bacteria refer to the photosynthetic bacteria in the proteobacteria alpha subdivision, i.e. the purple non-sulfur bacteria. Purple non-sulfur bacteria are widely distributed in freshwater, marine, soil and hot-spring environments. They have various metabolic pathways for the degradation of organic wastes. They also have a more digestible bacterial cell wall, and are rich in proteins, carotenoids, biological cofactors, and vitamins (Kobayashi and Kurata, 1978). The species currently used in Chinese aquaculture are Rhodopseudomonas palustris, Rubrivivax gelatinosa, Rhodobacter capsulata, R. spaheroides, Phaeospirillum fulvum, etc (Fig. 1). Those are probably the earliest and the most widely used probiotics in China since the 1980s. It was reported that the addition of photosynthetic bacteria as food additives stimulated the growth of shrimp and fish (Zhang et al., 1988), enhanced the survival rate of fish larvae, and improved the production of scallop seed (Huang et al., 1990; Wang et al., 1994). They were also found to increase the population growth rate of live food such as Brachionus plicatilis (Xu et al., 1992). Furthermore, some plant and herb extracts were identified as growth promoter for the mass cultivation of photosynthetic bacteria (Xu et al., 1994). Nowadays, using photosynthetic bacteria as probiotics is common practice in many fish or shellfish hatcheries and farms in China. Instead of using homemade photosynthetic bacterial products, many farmers today are using concentrated and encapsulated commercial photosynthetic bacterial products. Many commercial photosynthetic bacterial products are labeled as either single or multiple species at concentrations higher than $10^{9} \mathrm{ml}^{-1}$, and are often combined with growth promoters or conditioners, and are claimed to have multifunctional effects such as improvement of water quality, enhancement of growth rate and prevention of disease.

\subsection{Antagonistic bacteria}

Bacterial antagonism is a common phenomenon in nature; therefore, microbial interactions play a major role in the equilibrium between

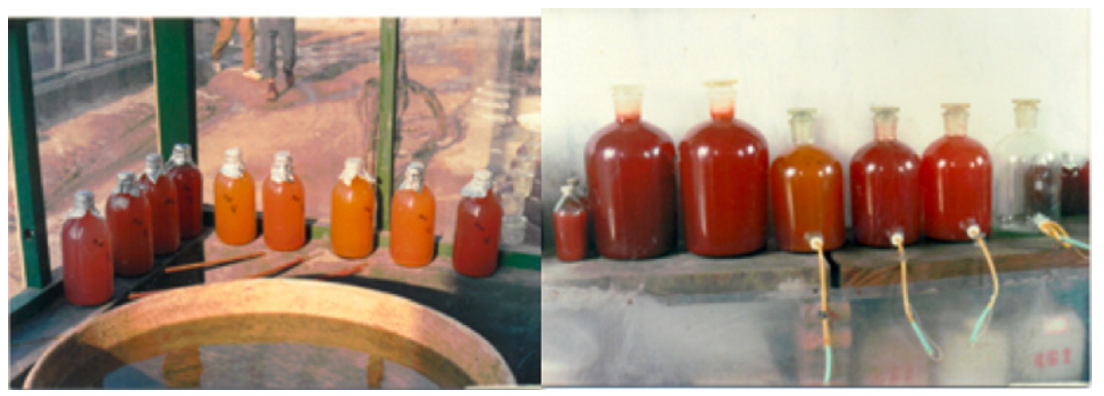

Fig. 1. Photosynthetic bacteria used in aquaculture of China. 
competing beneficial and potentially pathogenic microorganisms. The microbiota in the gastrointestinal tract of aquatic animals can be modified, for example, by ingestion of other microorganisms; therefore, microbial manipulation constitutes a viable tool to reduce or eliminate the incidence of opportunistic pathogens (Balcazar et al., 2006). In aquaculture, Pseudoalteromonas fluorescens has shown inhibitory effects against $V$. anguillarum. Mo et al. (2001), after screening 602 isolates from the aquaculture environment, identified a Vibrio-antagonistic strain $\mathrm{Q} 2$, which could inhibit 33 out of 37 Vibrio strains. Strain QJ2 was identified as Flavobacterium odoratum. Li et al. (2001) isolated five bacterial strains, from healthy penaeid shrimp and shrimp culture ponds, which could inhibit the bacterial pathogens of aquaculture animals. All these five strains belong to Alteromonas, and one strain A18 was identified as A. aurantia (now renamed as Pseudoalteromonas). It was found that A18 can produce an antimicrobial peptide in vitro and a reduction of the number of vibrios was achieved by applying the probiotic A18 to larvae culture of bay scallop (Argopecten irradians) (Wang et al., 2002a,b). Dong et al. (2007) isolated a bacterial strain DL2 from biofilm in sea water, and found it could inhibit various pathogenic Vibrio species, including $V$. anguillarum, $V$. harveyi, $V$. parahaemolyticus, etc. The strain DL2 was identified as Phaeobacter inhibens. Some autochthonous isolated Bacillus strains such as Bacillus subtilis are also being applied in aquaculture. They were isolated from fish gut or shrimp ponds, and antagonistic effects to pathogen Aeromonas hydrophila or decreased ammonia levels in culture water were found (Hu and Yang, 2006). Other Bacillus isolated from terrestrial livestock were used more frequently, and are the major source of probiotic species (Liu et al., 2002).

\subsection{Microorganisms for nutritional and enzymatic contribution to digestion}

Taking benefit from the experiences of non-aquaculture industries and also for safety reasons, some lactic acid bacteria and yeasts have been quickly accepted as probiotics in aquaculture. The most commonly used organisms in probiotic preparations are the lactic acid bacteria; these are found in large numbers in the gut of healthy animals and are, in the words of the American Food and Drug Administration (FDA), generally regarded as safe (GRAS status) (Parvez et al., 2006). In aquaculture in China, probiotic products containing lactic acid bacteria such as Lactobacillus and Bifidobacterium are investigated and market. However, the exact species or strain names are rarely found both in literature and are absent on the labels of the commercial products.

\subsection{Bacteria for improving water quality}

Organic enrichment and nitrogenous waste, including ammonium and ammonia are a serious concern in aquaculture. Nitrification is a process of transformation of ammonia to nitrate by two groups of bacteria, i.e. ammonia-oxidizing bacteria (oxidize ammonia to nitrite) and nitrite-oxidizing bacteria (oxidize nitrite to nitrate). This process can help to prevent to build up of toxic ammonia. Large amounts of commercial nitrifying bacteria (in $\mathrm{kg}$ ) are not widely available on the Chinese market. Aerobic denitrifiers are considered to be good candidates to reduce nitrate and/or nitrite to $\mathrm{N}_{2}$ under aerobic conditions in aquaculture water. Liao et al. (2006) isolated a new aerobic denitrifying strain X0412 from shrimp ponds, which was identified as Stenetrophomonas maltophilia. This denitrifying strain was found to contain the nitrite reductase gene nirs. Later on, 27 denitrifying bacterial strains (capable of both nitrate and nitrite reduction) were isolated from a shrimp pond. 16S rDNA sequence analysis revealed that the 27 bacterial strains belonged to 11 genera, including Pseudomonas, Halomonas, Acinetobacter, Paracoccus, Arthrobacter, Microbacterium, Cellulosimicrobium, Bacillus, Stenotrophomas and Sphingobacterium (Wang et al., 2007a,b). Currently there is strong tendency to combine the photosynthetic bacteria, Bacillus, nitrifiers and denitrifiers, therefore the probiotic compounds are often labeled as multifunctional and can be applied to different culture species in various culture conditions (Wang and Wang, 2008).

\subsection{Bdellovibrio}

Bdellovibrio spp. are motile Gram-negative $\delta$-proteobacteria that attack other Gram-negative cells, penetrate their periplasm, multiply in their cytoplasm, and finally bursting the host cell envelopes to start a new cycle (Jurkevitch, 2007). While Micavibrio, Vampirovibrio, and Vampirococcus have been reported to be able to grow upon microorganisms of only a single genus, Bdellovibrio as a group can utilize any of a wide variety of Gram-negative bacteria as a substrate cell. For example, B. bacteriovorus 109J can be grown on certain strains of Escherichia, Pseudomonas, Rhizobium, Chromatium, Spirillum, as well as other genera (Ruby, 1991). In mixed prey cell populations, $B$. bacteriovorus 109J does not randomly infect prey cells but infects and kills some prey more readily than others (Rogosky et al., 2006). Bdellovibrio were intensively studied in the 1960s and 1970s with the developmental stages observed microscopically and partially assayed biochemically (Lambert et al., 2006). The characteristic life-cycle of Bdellovibrio makes them attractive candidates for a number of applications concerning reducing or modulating bacterial populations, i.e. biological control of pathogens, water purification, and biofilm control (Yair et al., 2003). Worldwide little emphasis has been put on studying the possible role of Bdellovibrio in agricultural applications, except in China, where the use of Bdellovibrio for animal production was authorized by the Ministry of Agriculture in 1994. Especially in recent years, it was reported that using Bdellovibrio in aquaculture contributed to improved performance of fish, shrimp, crab and sea cucumber (Zhao, 2002; Cai and Zhao, 2006). Shen et al. (2008) considered that adequate amount of pathogens are required to obtain significant lysis effect of Bdellovibrio. Using a combination of Bdellovibrio and photosynthetic bacteria, better survival rates were obtained for Chinese mitten crab, Eriocheir sinensis (Chen et al., 2003) and the numbers of vibrios were found to be two order lower than in the controls in the cultured pufferfish Fugu obscurus (Qin, 2007). It is believed that using Bdellovibrio as biocontrol agent has a bright prospect in the future.

\subsection{Commercial probiotics}

In the middle of 1990s, commercial probiotics products from USA, Japan and United Kingdom were introduced into China. The first three commercial probiotics that were introduced were "Allelopathy" from Araya in Japan (antagonistic bacteria), probiotics from Alken-Murray Corp, USA (for degrading organic waste) and immune-stimulants from AGA Group, UK. The trial experiments were conducted in penaeid shrimp hatcheries in Dahua Aquaculture Company, Laizhou, Shandong Province, and were found to produce beneficial effects to penaeid shrimp. Since then, commercial probiotics became popular in China. Currently, the most popular one in China is Effective Microorganisms (EM) from Dr. Teruo Higa's EM Technology, Japan. The original developer of the technology that combines microorganisms for various beneficial uses, the Japanese agronomist Higa named his discovery "Effective Microorganisms ${ }^{\mathrm{TM}}$ " or "EM" and started to use the term internationally in 1986 (http://www.emrochina.com/doc). EM consists of a group of beneficial and non-pathogenic microorganisms, such as lactic acid bacteria, photosynthetic bacteria, yeasts and Actinomyces. EM has been stated to have the capacity to degrade the environmental and culture wastes and produce various beneficial effects (such as health effects) contributing to more sustainable technologies at a low cost (EM Technology Network, http://www. emtech.org/). After many years of applications, EM appears to play a great role in the agriculture sector in China. Annual EM production probably reaches up to 10,000 tonnes. In aquaculture, EM was used in 
both freshwater and marine culture for many species such as shrimp, water tortoise, carp, eel, abalone etc ( $\mathrm{Li}$ and Ni, 1995; Liu et al., 2006). A number of studies support the beneficial effects of EM. It was reported that EM could increase significantly the amino acid and vitamin B family contents of culture water, decrease the COD level in ponds and improve disease resistance in target organisms. Evidence for a higher food conversion ratio and digestive enzymes activities in the gut, for increased hemoglobin levels and numbers of red blood cells was also found (Huang et al., 1999; Li et al., 2002; Wu et al., 2004; Ye et al., 2004).

The EM technology was also developed in China based on autochthonous microorganisms isolated from different regions in China by the China National Microorganism Conservation Center. In their formula, no genetically engineered species were used, and no microbes have been imported from other countries. Currently the demand for EM in aquaculture is high, and commercial EM products and similar products for aquaculture are widely available on the market. However, the exact composition of different EM products specifically for aquaculture has not been described.

With the increased public concern on the use of antibiotics in aquaculture, it is not surprising to see a rapid growth of the probiotic industry for aquaculture. In 1999, the Ministry of Agriculture of China noticed that only ten bacterial species and two yeasts species were permitted to be used directly as feed. However, the microbial species currently used in probiotic products are rarely indicated and the existing species in probiotic products appear much more numerous than those permitted. Clearly, the government policy development lags behind the dynamic evolutions in the probiotic market and the lack of criteria to assure quality is obvious. In 2006, over 100 aquacultural microbial agent producers gathered in Shanghai to start defining their own industrial criteria and 90 companies signed the self-discipline agreement for quality control. At present, criteria defining the safety of probiotics for aquaculture are urgently needed. In food and pharmaceutical industries, the factors that must be addressed in the evaluation of safety of probiotics include pathogenicity, infectivity, toxicity, metabolic activity, and the intrinsic properties of the microbes (Ishibashi and Yamazaki, 2001). Moreover, commercial probiotics produced in other countries actually introduces exotic microorganisms. Therefore, it enlarges all the possible hazardous aspects relate to it, including the potential for genetic transfer of antibiotics resistance factors, occupation of niches and changes in the microbial food web. However, rigorous safety assessment for novel commercial probiotics and especially mixed probiotic productions for aquaculture in China still needs to be established.

In the last few years, the successful application of several probiotic products in commercial aquaculture of China have substantiated the efficacy of probitoics. It was reported that the application of EM in commercial freshwater prawn (Penaeus orientalis) cultures achieved an increased output valuing up to $103 \%$ (Hua et al., 2001). Improved efficacies were also found for silver carp (Hypophthalmichthys molitrix), bighead carp (H. nobilis), grass carp (Ctenopharyngodon idellus) and black carp (Mylopharyngodon piceus) cultures upon the application of EM, and an attractive input-output ratio (1:4.38) was achieved (Hua et al., 2001; Tian and Ma, 2008). Similarly, using photosynthetic bacterial products, the farmers were able to reduce $7 \%$ of their total costs for silver carp and bighead carp cultures (Xu and Xiao, 2006).Zhong and Guang (2008) applied the photosynthetic bacteria, Bacillus spp. and EM at different stages of Penaeus vannamei pond cultures, increasing the average per hectare up to 6400 Euro. Nowadays, the costs of using microbial agents for shrimp culture per production season are approximately 1500 Euro per hectare in the south of China Guangdong province. However, the lack of data on the efficacy of probiotics in commercial aquaculture is still jeopardising the sustained use of probiotics. At the beginning of 2008 , a hastily $50 \%$ decline of the probiotic market for commercial aquaculture was observed in the south of China, showing the weak confidences of farmers.

\section{Studies on probiotics quality control in aquaculture}

FAO has now designated the use of probiotics as a major means for the improvement of aquatic environmental quality (Subasinghe et al., 2003). Most studies on the effects of probiotics on cultured aquatic animals have emphasized a reduction in mortality or the improved resistance against putative pathogens (Irianto and Austin, 2002). However, the beneficial effects are sometimes temporal, depending on the time of exposure (Verschuere et al., 2000). As most fish contain a specific intestinal microbiota established at the juvenile stage (Olafsen, 2001), the colonization of probiotics to fish intestines requires adequate probiotics presented in ambient microbial community (MC) and their interaction with MC should not be neglected.

Commercial probiotic production should take into account beneficial traits of strain useful during industrial processing. To overcome the problem of inactivation during the manufacturing process, aquaculture industries try to improve the technology by screening for more resistant strains or alternatively by protecting the probiont through micro-bioencapsulation. By monitoring probiotics and the microbial community structure and dynamics in the manufacture process and in vivo culture system, the viability and effects of probiotics can be documented in detail. For this purpose, nucleic acid-based techniques have been used. Highly discriminative molecular methods such as 16S rRNA gene sequencing and oligonucleotide probes can also be used for accurate probiotic species labeling, which is important for responsible quality control efforts, to build consumer confidence in product labeling, and for safety considerations (Yeung et al., 2002). The reliable identification of probiotics requires molecular methods with a high taxonomic resolution that are linked to up-to-date identification libraries.

\section{Molecular techniques for evaluation of commercial probiotics}

Currently the consumer, the industry as well as legislative authorities urgently require sensitive and reliable methods to identify and characterize the microbial content of probiotics (McCartney, 2002). Conventional methods relying on phenotypic characterization, growth requirements and characteristics, fermentation profiles, and serology studies have been proven useful but carry inherit deficiencies. To date, various molecular fingerprinting techniques, using different genetic markers, have proven useful in subspecies discrimination or strain differentiation. A number of studies evaluated the bacterial composition of commercial probiotic products for human consumption (Fasoli et al., 2003; Temmerman et al., 2003; Huys et al., 2006). Despite the availability of various molecular techniques, reports on the evaluation of the composition of probiotic products in China are rare. Recent Chinese reports, using ERIC-PCR and PCRDGGE/TGGE to analyse microbial fertilizers (Hu and Yang, 2006), showed that these methods are fast and accurate.

\subsection{PCR-DGGE/TGGE techniques}

Of the many molecular methods for the investigation of specific groups or microbial community analysis, PCR-DGGE/TGGE is the most widely used. Profiling the 16S rRNA population by DGGE and TGGE enables the rapid estimation of the presence and relative abundance of microorganisms in a sample (Muyzer et al., 1993). The general principle of DGGE/TGGE is the separation of fragments of the individual rRNA genes based on differences in chemical stability or melting temperature of these genes. After more than a decade of application in microbial population studies, the DGGE/TGGE technique gradually reaches maturity. To allow comparative analysis of various probiotic products and to evaluate the composition changes with increasing shelf life, as well as to investigate the specific probiotics in actual culture samples, the method must be carefully assessed and standardized. The sample size/volume, DNA extraction 
efficiency, PCR biases and interference of DNA from dead bacterial cells should be carefully examined and optimized (Bostrom et al., 2004; Nocker et al., 2006). To examine reproducibility and reduce experimental errors, internal standards could be used throughout the DNA extraction and PCR-DGGE (Petersen and Dahllof, 2005). The use of internal standards significantly reduced variation among replicate samples and was shown to accurately describe changes in relative abundance in an environmental sample using PCR-DGGE. In our study, we quantitatively added viable E. coli cell and plasmid DNA as control spiking DNA in commercial probiotic products which consisted of Bacillus spores; the results in Fig. 2 show that the optimal sample size, detection limitation of number of viable cells and the reproducibility of PCR-DGGE can be demonstrated.

\subsection{FISH technique}

Although PCR-based fingerprinting is the most sensitive technique to detect sequences that are present in very low concentrations in the samples, many factors can influence the amplification reaction and the fingerprinting techniques alone often do not provide sufficient quantitative data (v. Wintzingerode et al., 1997). FISH with rRNA target probes has been developed for the in situ identification of single microbial cells and is the most commonly applied among the "nonPCR-based' molecular techniques (Amann et al., 1990). This method is based on the hybridization of synthetic oligonucleotide probes to specific regions within the bacterial ribosome and does not require cultivation. The FISH technique can be applied for the in situ detection of probiotic Lactobacillus cells in faecal and biopsy samples. The potential of flow cytometry in combination with FISH has recently been demonstrated for Bifidobacteria in faecal samples (Vaughan et al., 1999). Due to its speed and sensitivity, this technique is considered a powerful tool for phylogenetic, ecological, diagnostic and environmental studies in microbiology (Bottari et al., 2006). In our study indicated in Fig. 3, we applied the FISH technique to characterize a probiotic photosynthetic bacteria mixture used in aquaculture. Through the use of group or species-specific probes, it is possible to identify different bacterial groups in complex probiotics mixtures, thus providing quantitative information for the understanding of the probiotics mixture and the possible interspecies interaction.

Although other advanced methods such as terminal restriction fragment length polymorphism (T-RFLP), multilocus sequence typing

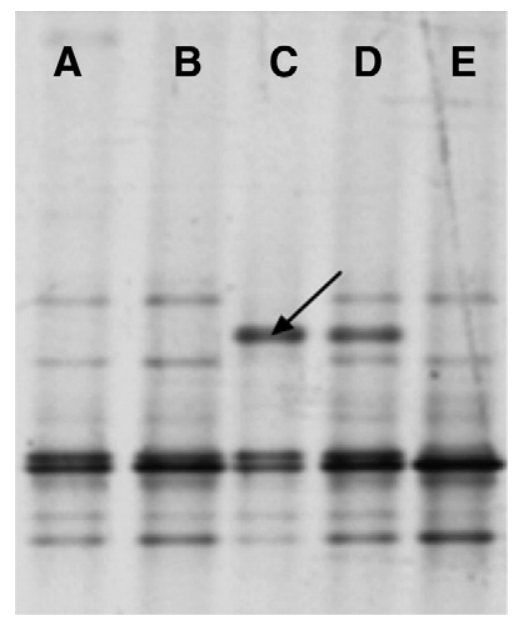

Fig. 2. DGGE gel patterns of analysis of probiotic samples (mainly Bacillus spores) with addition of E. coli cells. (Lane A: $0.1 \mathrm{mg}$ probiotic samples used for DNA extraction; Lane B: $1 \mathrm{mg}$ probiotic samples used for DNA extraction; Lane C: $0.1 \mathrm{mg}$ probiotic samples with the addition of $10^{9}$ viable E. coli used for DNA extraction; Lane D: $1 \mathrm{mg}$ probiotic samples with the addition of $10^{9}$ viable E. coli used for DNA extraction; Lane E: $10 \mathrm{mg}$ probiotics samples with $10^{9}$ viable $E$. coli cells used for DNA extraction; Arrow indicates band representing $E$. coli).

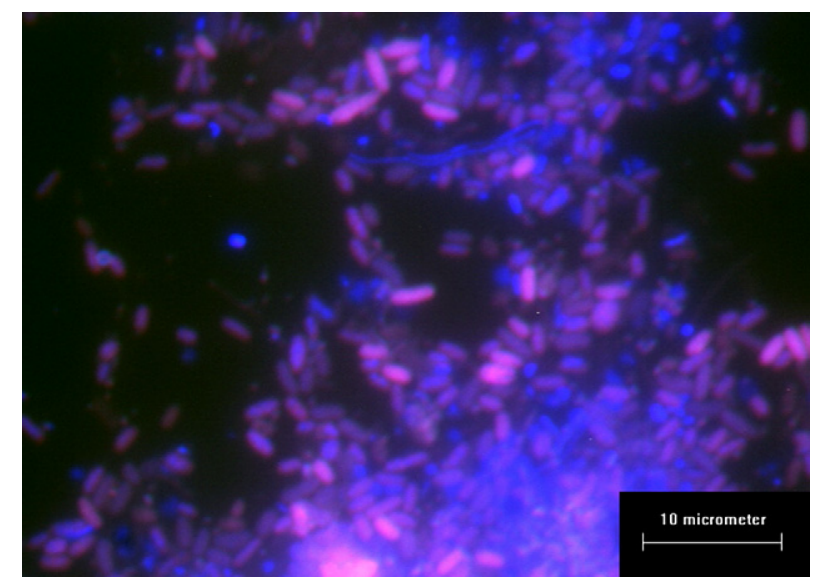

Fig. 3. Epifluorescence micrographs of a mixture of photosynthetic bacteria probiotic products. Bacterial cells (pink in colour figure; light grey in black and white figure) were detected by in situ hybridization with TAMRA-labeled oligonucleotide probe for proteobacteria $\alpha$ subdivision. Bacterial cells (blue in colour figure; grey in black and white figure) are DAPI stained. Bar $=10 \mu \mathrm{m}$. (For interpretation of the references to colour in this figure legend, the reader is referred to the web version of this article.)

(MLST) and Fluorescence amplified fragment length polymorphism (FAFLP) are available, currently PCR-DGGE with FISH technique are proven effective, sensitive and inexpensive and therefore can widely be applied in probiotics studies. Because various phylogenetic and functional genes can be selected for PCR-DGGE and FISH analysis, both methods possess great potential and flexibility to study various probiotic products. Nowadays, plenty of primers and probes sources are available for distinction of Bacillus, lactic bacteria and Bifidobacteria species. Primers or probes for $16 \mathrm{~S}$ rRNA gene region or 16S-23S rRNA gene intergenic spacer region as well as functional genes can readily be applied to describe specific strains and group function within a sample.

\section{Prospects}

Overall, the research of probiotics in aquaculture of China is still in its early stage, and not much of commercial probiotics products were licensed in China so far. Scientists in China will continue to screen new probiotic strains from local aquaculture rearing unit to suit the specific requirement in China. In the near future, probiotics will gain more popularity in aquaculture of China, and the application areas will be expanded. Also, quality control of probiotics in aquaculture of China will become an important issue. With the increased use of molecular methods for the definitive analysis of the bacterial components of probiotic products and for in vivo validation, it is expected that both the probiotics quality and functional properties can significantly be improved in China. This type of research can aid for the development of adequate technology for the evaluation of the efficiency of microbial agents as probiotics in aquaculture.

\section{Acknowledgments}

This work was supported by an ICP PhD scholarship from the Flemish Interuniversity Council (VLIR), Belgium, grants from National Natural Science Foundation of China (project no. 30500377 and 40876067), and a grant from the National High Technology Research and Development Program of China (863 Program, project no. 2007AA09Z434).

\section{References}

Amann, R.I., Binder, B.J., Olson, R.J., Chisholm, S.W., Devereux, R., Stahl, D.A., 1990. Combination of 16S rRNA-targeted oligonucleotide probes with flow cytometry for analyzing mixed microbial populations. Appl. Environ. Microbiol. 56, 1919-1925. Balcazar, J.L., Blas, I.d., Ruiz-Zarzuela, I., Cunningham, D., Vendrell, D., Muzquiz, J.L., 2006. The role of probiotics in aquaculture. Vet. Microbiol. 114, 173-186. 
Bondad-Reantaso, M.G., Subasinghe, R.P., Arthur, J.R., Ogawa, K., Chinabut, S., Adlard, R., Tan, Z., Shariff, M., 2005. Disease and health management in Asian aquaculture. Vet. Parasitol. 132, 249-272.

Bostrom, K.H., Simu, K., Hagstrom, A., Riemann, L., 2004. Optimization of DNA extraction for quantitative marine bacterioplankton community analysis. Limnol. Oceanogr.: Methods 2, 365-373.

Bottari, B., Ercolini, D., Gatti, M., Neviani, E., 2006. Application of FISH technology for microbiological analysis: current state and prospects. Appl. Microbiol. Biotechnol. 73, 485-494.

Bryant, D.A., Frigaard, N.U., 2006. Prokaryotic photosynthesis and phototrophy illuminated. Trends Microbiol. 14, 488-496.

Cai, J.P., Zhao, J., 2006. The recent research progress on Bdellovibrio bacteriourus. Acta Microbiol. Sin. 6, 1028-1032 (In Chinese, With English abstract).

Chen, J.C., Hu, G.D., Wu, W., 2003. Studies on the application of probiotics in the culture of Chinese mitten crab, Eriocheir sinensis Period. Shanghai Fish. Univ. 12, 271-273 (in Chinese, with English abstract).

Dong, X., Li, Y., Zhang, X.-H., Liu, J., Hu, Z., Chen, J., 2007. Identification and inhibitory activity to pathogenic Vibrio species of a marine bacterium Phaeobacter DL2. J. Fishery Sci. China 14, 996-1003 (in Chinese, with English abstract).

FAO, 2006. State of world aquaculture: 2006. Fisheries Department, Food and Agriculture Organization of the United Nations, Rome, Italy.

Fasoli, S., Marzotto, M., Rizzotti, L., Rossi, F., Dellaglio, F., Torriani, S., 2003. Bacterial composition of commercial probiotic products as evaluated by PCR-DGGE analysis. Int. J. Food Microbiol. 82, 59-70.

Fuller, R., 1989. Probiotics in man and animals. J. Appl. Bacteriol. 66, 365-378.

$\mathrm{Hu}, \mathrm{K} .$, Yang, X.L., 2006. Current progress of microbial ecological agents in aquaculture in China. Fish. Mod. 6, 36-38 (in Chinese).

Hua, R.S., Ge, L.L., Wang, J.P., Guo, X.D., 2001. The application of EM in aquaculture. Sci. Fish Farming 6, 41-42 (in Chinese).

Huang, H., Yao, Z., Zheng, J., 1990. The study of the applications of photosynthetic bacteria to aquaculture (3)-the value of using photosynthetic bacteria as the initial feed for fish larvae. J. Zhanjiang Fish. College 10, 58-61 (in Chinese, With English abstract).

Huang, Y.C., Wang, S.L., Yang, Z.C., Li, C.N., 1999. Effect of effective microorganisms (EM) on the bacteria in intestinal tract and protease activity in the intestine and hepatopancreas of Jian carp. Fujian Fish. 1, 24-29 (in Chinese).

Huys, G., Vancanneyt, M., D'Haene, K., Vankerckhoven, V., Goossens, H., Swings, J., 2006. Accuracy of species identity of commercial bacterial cultures intended for probiotic or nutritional use. Res. Microbiol. 157, 803-810.

Irianto, A., Austin, B., 2002. Probiotics in aquaculture. J. Fish Dis. 25, 633-642.

Ishibashi, N., Yamazaki, S., 2001. Probiotics and safety. Am. J. Clin. Nutr. 73, 465-470.

Jurkevitch, E., 2007. Predatory behaviors in bacteria-diversity and transitions. Microbe, Am. Soc. Microbial. 2, 67-73.

Kim, S., Nonaka, L., Suzuki, S., 2004. Occurrence of tetracycline resistance genes tet(M) and tet(S) in bacteria from marine aquaculture sites. FEMS Microbiol. Lett. 237, 147-156.

Kobayashi, M., Kurata, S., 1978. The mass culture and cell utilization of photosynthetic bacteria. Process Biochem. 13, 27-30.

Lambert, C., Morehouse, K.A., Chang, C.Y., Sockett, R.E., 2006. Bdellovibrio: growth and development during the predatory cycle. Curr. Opin. Microbiol. 9, 639-644.

Lan, J., Zhang, X.-H., Wang, Y., Chen, J., Han, Y., 2008. Isolation of an unusual strain of Edwardsiella tarda from turbot and establish a PCR detection technique with the gyrB gene. J. Appl. Microbiol. doi:10.1111/j.1365-2672.2008.03779.x.

Lei, Q.L., 2007. Promotion for the healthy development of industrial mariculture appearing of the famous brand turbot with electronic labels on the market. Oceanogr. Limnol. Sin. 38, 186 (in Chinese).

Li, W.J., Ni, Y.Z., 1995. Effective microorganisms research and its application. Chin. J. Ecol. 14 (5), 58-62.

Li, H., Yu, Y., Li, Y., Chen, G., Ji, W., Xu, H., 2001. Selection and identification of marine probiotics. High Technol. Lett. 11, 18-22 (in Chinese, With English abstract).

Li, P., Zhu, Y., Jiang, H.Y., 2002. Application of EM in the cultures of Macrobrachium rosenbergii. J. Aquac. 4, 23-24 (in Chinese).

Liao, S., Zheng, G., Wang, A., Huang, H., Sun, R., 2006. Isolation and characterization of a novel aerobic denitrifier from shrimp pond. Acta Ecol. Sin. 26 (11), 3018-3724 (in Chinese, With English abstract).

Liu, X.M., Nie, J.H., Wang, Q.R., 2002. Research progress in the probiotics of compound microorganisms. Chin. J. Eco-Agriculture 10 (4), 80-83 (in Chinese).

Liu, S.X., Xie, Q.S., Yang, Z.C., 2006. Status and prospect of application EM in aquaculture. Hebei Fish. 12, 5-7 (in Chinese).

McCartney, A.L., 2002. Application of molecular biological methods for studying probiotics and the gut flora. Br. J. Nutr. 88, 29-37.

Mo, Z., Yu, Y., Li, H., Li, Y., Ji, W., Xu, H., 2001. Selection of vibrios-antagonism bacteria. Period. Ocean Univ. Qingdao 31 (2), 225-231.

Muyzer, G., de Waal, E.C., Uitterlinden, A.G., 1993. Profiling of complex microbial populations by denaturing gradient gel electrophoresis analysis of polymerase chain reaction-amplified genes coding for 16S rRNA. Appl. Environ. Microbiol. 59, 695-700.

Nocker, A., Cheung, C.Y., Camper, A.K., 2006. Comparison of propidium monoazide with ethidium monoazide for differentiation of live vs. dead bacteria by selective removal of DNA from dead cells. J. Microbiol. Methods 67, 310-320.

Olafsen, J.A., 2001. Interactions between fish larvae and bacteria in marine aquaculture. Aquaculture 200, 223-247.

Parvez, S., Malik, K.A., A.h., Kang, S., Kim, H.Y., 2006. Probiotics and their fermented food products are beneficial for health. J. Appl. Microbiol. 100, 1171-1185.

Petersen, D.G., Dahllof, I., 2005. Improvements for comparative analysis of changes in diversity of microbial communities using internal standards in PCR-DGGE. FEMS Microbiol. Ecol. 53, 339-348.
Qin, S.J., 2007. Application of Bdellovibrios microecologics in the culture of freshwater animals. Fish. Sci. Technol. Info. 34, 221-223 (in Chinese).

Rogosky, A.M., Moak, P.L., Emmert, E.A.B., 2006. Differential predation by Bdellovibrio bacteriovorus 109. J. Curr. Microbiol. 52, 81-85.

Ruby, E.G., 1991. The genus Bdellovibrio, In: Balows, A., Truper, H.G., Dworkin, M., Harder W., Schleifer, K.H. (Eds.), The Prokaryotes, 2nd Edn. , pp. 3400-3415.

Shen, Q., Xie, R.L., Lv, W.Q., Sun, W.J., Lu, Z.G., 2008. Status and prospect of using Bdellovibrio in aquaculture. Hebei Fish. 178, 1-5 (in Chinese)

Smith, P., Hiney, M.P., Samuelsen, O.B., 1994. Bacterial resistance to antimicrobial agents used in fish farming: a critical evaluation of method and meaning. Annu. Rev. Fish Dis. 4, 273-313.

Sørum, H., 2006. Antimicrobial drug resistance in fish pathogens. In: Aarestrup, F.M (Ed.), Antimicrobial Resistance in Bacteria of Animal origin. ASM Press, Washington DC, pp. 213-238.

Subasinghe, R.P., 2005. Epidemiological approach to aquatic animal health management: opportunities and challenges for developing countries to increase aquatic production through aquaculture. Prev. Vet. Med. 67, 117-124.

Subasinghe, R.P., Curry, D., McGladdery, S.E., Bartley, D., 2003. Recent technological innovations in aquaculture. Review of the State of World Aquaculture, FAO Fisheries Circular, pp. 59-74.

Temmerman, R., Pot, B., Huys, G., Swings, J., 2003. Identification and antibiotic susceptibility of bacterial isolates from probiotic products. Int. J. Food Microbiol. 81, $1-10$.

Tian, C.K., Ma, Z.W., 2008. The application of the originated EM for the commercial freshwater fish cultures. Heilongjiang Fish 3, 18-19 (in Chinese).

Tseng, C.K., 1993. Notes on mariculture in China. Aquaculture 111, 21-30.

Vaughan, E.E., Mollet, B., deVos, W.M., 1999. Functionality of probiotics and intestinal lactobacilli: light in the intestinal tract tunnel. Curr. Opin. Biotechnol. $10,505-510$.

Verschuere, L., Rombaut, G., Sorgeloos, P., Verstraete, W., 2000. Probiotic bacteria as biological control agents in aquaculture. Microbiol. Mol. Biol. Rev. 64, 655-671.

v. Wintzingerode, F., Gobel, U.B., Stackebrandt, E., 1997. Determination of microbia diversity in environmental samples: pitfalls of PCR-based rRNA analysis. FEMS Microbiol. Rev. 21, 213-229.

Wang, Y.M., Wang, Y.G., 2008. Advance in the mechanisms and application of microecologics in aquaculture. Prog. Vet. Med. 29, 72-75 (in Chinese).

Wang, X., Sun, Z., Liu, X., Ma, J., Wang, B., Song, X., Zhu, Z., Shi, J., Wang, F., 1994 Application of photosynthetic bacteria in scallop artificial seed breeding. J. Fish Chin. 18, 65-68 (in Chinese, With English abstract).

Wang, Q.Y., Cai, S.L., Li, J., 1997. The shrimp farming industry in China. World Aquac. 28, 23-29 (in Chinese).

Wang, B., Yu, J., Li, Y., Ji, W., Xu, H., 2002a. Isolation and identification of pathogen (Vibrio harveyi) from sea perch, Lateolabrax japonicus. J. Fish. Sci. Chin. 1, 52-55 (in Chinese With English abstract).

Wang, X., Du, Z., Chen, G., Li, Y., Ji, W., Xu, H., 2002b. Application of probiotic A18 to larvae culture of bay scallop (Argopecten irradians). Chin. High Technol. Lett. 8, 86-90.

Wang, A., Zheng, G., Liao, S., Huang, H., Sun, R., 2007a. Diversity analysis of bacteria capable of removing nitrate/nitrite in a shrimp pond. Acta Ecol. Sin. 27 (5) 1937-1943 (in Chinese, With English abstract).

Wang, Y., Han, Y., Li, Y., Chen, J., Zhang, X.-H., 2007b. Isolation of Photobacterium damselae subsp. piscicida from diseased tongue sole (Cynoglossus semilaevis Gunther) in China. Acta Microbiol. Sin. 47, 763-768 (in Chinese, With English abstract).

Wei, Q., 2002. Social and economic impacts of aquatic animal health problems in aquaculture in China. In: Arthur, J.R., Phillips, M.J., Subasinghe, R.P., Reantaso, M.B., MacRae, I.H. (Eds.), Primary Aquatic Animal Health Care in Rural, Small-Scale, Aquaculture Development. FAO Fish. Tech. Pap. No. 406, pp. 55-61.

World Health Organization. 1999. Joint FAO/NACA/WHO Study Group on food safety issues associated with products from aquaculture. WHO Technical Report Series, No 883.

World Health Organization. 2006. Report of a joint FAO/OIE/WHO expert consultation on antimicrobial use in aquaculture and antimicrobial resistance: Seoul, Republic of Korea, 13-16 June 2006.

Wu, L., Wang, Y.M., Xu, Q., Wei, F.J., 2004. The influence of EM to the haematological parameters of Southern catfish (Silurus meriaionalis Chen). Feed Res. 5, 7-10 (in Chinese).

Xiao, H., Li, Y., Wang, X.H., Ji, W.S., Xu, H.S., 1999. Studies on pathogens of rotted gill and rotted caudal fins of seaperch (Laterolabrax japonicus) fry. J. Ocean U. Qingdao 29, 87-93 (in Chinese, With English abstract).

$\mathrm{Xu}$, J.H., Xiao, K.Y., 2006. Application and development prospect of microecological preparation in aquaculture. Hebei Fish. 146, 54-56 (In Chinese, with English abstract).

Xu, B., Ding, M., Mao, J., Xu, H., 1992. The food value of Rhodopseudomonas sphaeroides for Brachionus plicatilis. Trans. Oceanol. Limnol. 2, 17-22 (in Chinese, With English abstract).

Xu, B., Zhou, X., Xu, H., Shi, J., 1994. Promotion of plant extract on growth of photosynthetic bacteria. J. Ocean U. Qingdao 24, 47-51 (in Chinese, With English abstract).

Yair, S., Yaacov, D., Susan, K., Jurkevitch, E., 2003. Small eats big: ecology and diversity of Bdellovibrio and like organisms, and their dynamics in predator-prey interactions. Agronomie 23, 433-439.

Ye, M.B., Gu, H.X., Chen, H.L., Lin, R.J., 2004. Application of EM in the cultures of juvenile green sea turtle (Chelonia mydas). Chin. Fish. 6, 51-52 (in Chinese).

Yeung, P.S.M., Sanders, M.E., Kitts, C.L., Cano, R., Tong, P.S., 2002. Species-specific identification of commercial probiotic strains. J. Dairy Sci. 85, 1039-1051. 
Zhang, D., Sun, Q., Naihong, C., Qiao, Z., 1988. Isolation and cultivation of photosynthetic bacteria of Rhodospirillaceae and its application as additive in feeds of fish and prawn. J. Fish. Chin. 12, 367-369 (in Chinese).

Zhao, M.S., 2002. Role of Bdellovibrio bacteriovorus on treatment and prevention of shrimp and crab diseases and application method. Mod. Fish. Info. 17, 14-16 (in Chinese).
Zhong, W.H., Guang, Z.C., 2008. The application efficacy of microecological agents in Penaeus vannamei pond culture. Tianjin Fish. 2, 19-23 (in Chinese).

Zhong, Y., Power, G., 1997. Fisheries in China: progress, problems, and prospects. Can. J. Fish. Aquat. Sci. 54, 224-238. 